\title{
Comparison of two methods used for monitoring low-copy cytomegalovirus infection in a patient with chronic myeloid leukemia after unrelated umbilical cord blood transplantation
}

\author{
Tomasz Dzieciątkowski ${ }^{1}$, Maciej Przybylskii ${ }^{1}$, Agnieszka Tomaszewska ${ }^{2,}{ }^{3}$, \\ Małgorzata Rokicka ${ }^{2}$ and Mirosław Łuczak $^{1}$
}

${ }^{1}$ Chair and Department of Medical Microbiology, Medical University of Warsaw, Warsaw, Poland

${ }^{2}$ Department of Hematology, Oncology and Internal Medicine, Medical University of Warsaw, Warsaw, Poland

${ }^{3}$ Department of Hemopoietic Stem Cell Transplantation, Institute of Hematology and Transfusion Medicine, Warsaw, Poland

Received: 2006.08.31, Accepted: 2007.02.28, Published online first: 2007.06.08

\begin{abstract}
Introduction: Detection of human cytomegalovirus (CMV, HHV-5) DNA in clinical specimens is considered a cornerstone in the diagnosis of HHV-5 disease. The present study compared two quantitative methods used for diagnosing cytomegalovirus infection in a 21-year-old woman with chronic myeloid leukemia after an unrelated umbilical cord blood transplantation.

Materials and Methods: Blood samples were tested for the presence of HHV-5 DNA using the LightCycler PCR, the quantitative Eclipse ${ }^{\circledast}$ CMV DNA Detection Kit, and a qualitative in-house PCR assay using primers that amplify part of the HHV-5 MIE gene.

Results: Results from samples containing a low cytomegalovirus load were more accurate with the LightCycler test than those obtained with the Eclipse ${ }^{\circledR}$ test, which underestimated the viral load of samples containing low DNA copy numbers.

Conclusions: These findings underline the value of novel PCR methods used in current therapeutic procedures and in monitoring antiviral therapy with nucleoside analogs. The high level of sensitivity, specificity, accuracy, and rapidity provided by the LightCycler instrument are favorable for the use of this system in the detection of HHV-5 DNA in clinical specimens.
\end{abstract}

Key words: chronic myeloid leukemia, umbilical cord blood transplantation, cytomegalovirus infection, real-time PCR.

Corresponding author: Tomasz Dzieciątkowski, Chair and Department of Medical Microbiology, Medical University of Warsaw, Chałubińskiego 5, $02-004$ Warsaw, Poland, fax: +48 22 599-17-78, e-mail: dzieciatkowski@wp.pl

\section{INTRODUCTION}

Human herpesvirus 5 (HHV-5, formerly CMV), from the $\beta$-Herpesvirinae subfamily, is widely spread within the population [9]. Primary HHV-5 infection is usually asymptomatic and leads to latent infection of macrophages, the $\mathrm{CD} 8^{+}$subpopulation of lymphocytes $\mathrm{T}$, and probably also endocrine glands cells [12]. HHV-5 infections are thus a serious matter of concern in the group of immunocompromised patients [9]. The most frequent clinical syndromes noted include cytomegalovirus pneumonia, myelosuppression syndrome [16], exacerbation of graft-versus-host disease (GvHD) [9], and increased risk of secondary bacterial and fungal infections [6]. In most laboratories, two main methods are used for the quantitative detection of $\mathrm{HHV}-5$ viremia; the first is based on PCR/hybridization/colorimetric detection of the product and the second is the real-time PCR technique[15].

Transplantation of allogenic hempoietic stem cells is a therapeutic option in many hematological malignancies, bone marrow deficiencies, and inherited immunodeficiency syndromes $[3,13,17]$. Because of the insufficient number of classic, HLA-matched donors of hempoietic stem cells, umbilical cord blood (UCB) has became considered an alternate and widely accepted source of hempoietic cells $[2,14,17]$. In adult graft recipients, the main limitation of UCB usage is the insufficient number of progenitor cells in the transplanted material $[3,13,17]$. A possible way to overcome 
this problem consists of transplanting multiple units of UCB from various unrelated donors (transplantation of so-called mixed UCB) $[1,7,17,18]$. UCB as the source of hempoietic stem cells, despite its particular disadvantages, has two considerable advantages: availability and low risk of viral contamination (especially with cytomegalovirus and Epstein-Barr virus) [17].

In this article, a case of infection-related complications (especially HHV-5 reactivation) in a patient with chronic myeloid leukemia after transplantation of two UCB units obtained from two unrelated donors is described along with a comparison and evaluation of the usefulness of two viral DNA detection methods (Fig. 1).

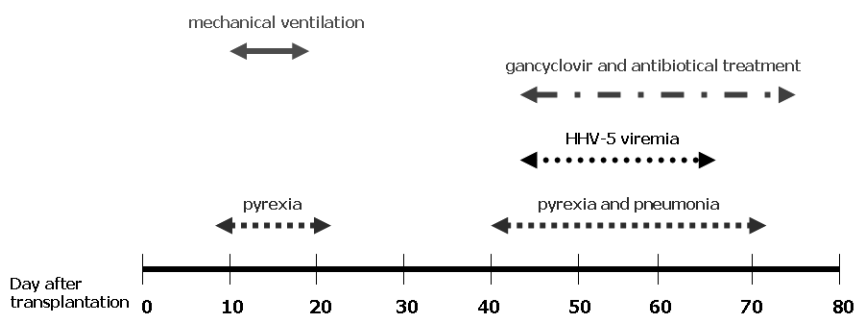

Fig. 1. Changes in the patient's clinical status over time after UCB transplantation.

\section{Case report}

Chronic myeloid leukemia $\mathrm{Ph}+$, bcr/abl+ in chronic phase was diagnosed in a 21-year-old woman in November 2001. The patient was initially treated with hydroxycarbamide, and subsequently interferon (IFN)- $\alpha$ (Intron A) therapy and then imatinib therapy (daily dose: $400 \mathrm{mg}$ ) were introduced. Taking into consideration the age of the patient, her resistance to both the IFN- $\alpha$ and imatinib treatments used before, and the lack of both related and unrelated matched donors, the patient was qualified for transplantation of two units of unrelated UCB [10, 14]. The calculated EBMT Risk Score [8], used for estimating the transplant-related mortality risk, was 3 . Pre-transplantation examination of the patient's bone marrow cells using fluorescent in situ hybridization revealed the presence of bcr/abl fusion in $100 \%$ of the analyzed cells. At this time the patient was anti-HHV-5 IgG seropositive, but the result for antiHHV-5 IgM antibodies was negative. Both donors were cytomegalovirus seronegative and compatible in four of the six examined HLA antigens (Table 1).

After myeloablative conditioning (BuCy200+ATG-Fresenius) on December 20, 2004 (3 years after diagnosis), $3.7 \times 10^{7} / \mathrm{kg}$ nuclear cells and $0.6 \times 10^{5} / \mathrm{kg} \mathrm{CD} 34^{+}$cells were transplanted in total. Oral acyclovir was used as a routine viral prophylaxis, fluconazole for the prevention of fungal infections, and cyclosporine A was introduced on day -1 as a prevention of acute GvHD. On day +9 after transplantation, during the period of myelosuppression, pyrexia in the patient was observed; empiric antibiotic therapy with a broad-spectrum agent was applied.
Table 1. Characteristics of the selected umbilical cord blood (UCB) units

\begin{tabular}{|c|c|c|c|c|c|}
\hline \multirow{2}{*}{$\frac{\text { UCB symbol }}{\text { DUCB5926 }}$} & \multicolumn{3}{|c|}{ HLA } & \multirow{4}{*}{$\begin{array}{l}\text { Blood group } \\
0 \text { Rh-positive } \\
\text { (ccDEeKell }{ }^{-} \text {) }\end{array}$} & \multirow{4}{*}{$\frac{\text { Sex }}{\text { female }}$} \\
\hline & $\underline{\mathrm{A}}$ & $\underline{\mathrm{B}}$ & $\underline{\mathrm{DRB} 1}$ & & \\
\hline & 24 & 38 & *0901 & & \\
\hline & 68 & 51 & $* 1301$ & & \\
\hline \multirow[t]{3}{*}{ DUCB7378 } & $\underline{\mathrm{A}}$ & $\underline{\mathrm{B}}$ & $\underline{\mathrm{DRB} 1}$ & \multirow{3}{*}{$\begin{array}{l}\text { A Rh-positive } \\
\left(\text { CcDeeKell }^{-}\right)\end{array}$} & \multirow[t]{3}{*}{ male } \\
\hline & 24 & 38 & *09XX & & \\
\hline & 26 & 51 & *13XX & & \\
\hline \multirow[t]{3}{*}{ PATIENT } & $\underline{\mathrm{A}}$ & $\underline{\mathrm{B}}$ & $\underline{\text { DRB1 }}$ & \multirow{3}{*}{$\begin{array}{l}\text { A Rh-positive } \\
\left(\mathrm{ccDEeKell}^{-}\right)\end{array}$} & \multirow[t]{3}{*}{ female } \\
\hline & 24 & 27 & *0901 & & \\
\hline & 25 & 38 & *1301 & & \\
\hline
\end{tabular}

Streptococcus mitis, sensitive to the antibacterial agents used, was isolated from the one of the patient's blood samples. On the next day $($ day +10$)$ the patient revealed respiratory insufficiency with gradually growing intensity. In chest X-ray massive alveolar infiltration was noted, mainly in both hilar regions. The decision to mechanically ventilate was taken. The patient was treated empirically with methylprednisolone, broad-spectrum antibiotics, antifungal agents, acyclovir, granulocyte colony-stimulating factor, and intravenous immunoglobulin G (IVIG). After this empirical treatment an improvement in respiratory function was noted, and on day +19 after transplantation the patient was extubated.

Diffuse changes of "milk-glass" appearance observed in both lungs in a control CT-scan of the chest were explained as atypical pneumonia. The results of microbiological and viral tests obtained during this period were negative. In routinely performed (twice weekly) qualitative PCR tests screening for HHV-5 [4], no cytomegalovirus DNA was detectable before day +42 after transplantation. The first blood sample with a detectable amount of viral DNA occurred on day +43 . Then intravenous ganciclovir $(5 \mathrm{mg} / \mathrm{kg}$ body weight every $12 \mathrm{~h}$ ) as a preemptive strategy was administered, at an HHV-5 viremia level of 1300 copies $/ \mathrm{ml}$. At the same time the patient presented with pyrexia and pneumonia of unclear etiology on x-ray and CT scans, so IVIG $(0.5 \mathrm{~g} / \mathrm{kg})$ was co-administered. Because the etiology of pneumonia was unclear, the patient received antibiotics (ceftriaxone and clarithromycin i.v.). This treatment (ganciclovir and antibiotics) was continued until day +75 after transplantation (until DNA HHV-5 results were negative in two subsequent tests).

Chimerism was regularly estimated with the microsatellite method. On day +30 , mixed chimerism was detected: $40 \%$ DUCB 7378 (male baby) donor cells and $60 \%$ recipient cells. In the cytogenetic examination of bone marrow cells performed on +50 day after transplantation, mixed chimerism was detected: improper mosaic kariotype 46, XX, th(7;11)(q11.2;q23), t(9;22) (q34;q11.2), and $\mathrm{t}(11 ; 17)(\mathrm{p} 11.2 ; \mathrm{p} 13)$ [7]/46XY [130]. The XY line came from the hempoietic stem cells of the donor. Finally, on day +90 the donor chimerism DUCB 7378 was detected in $100 \%$ of the analyzed cells. 
On day +78 after transplantation of UCB, the patient was transferred to the primary care center and still received periodical transfusions of platelet concentrates. Based on the information obtained from the physicians in charge of the patient outside of the Department of Hematology, Oncology, and Internal Medicine, it was determined that the patient had another three onsets of cytomegalovirus reactivation (in March, April, and June of 2005). From June of 2005 another problem of concern was therapy-resistant autoimmunohemolytic anemia with the presence of mixed $\operatorname{IgG}, \operatorname{IgM}$ and $\operatorname{IgA}$ antibodies. After using all available methods of therapy (methylprednisolone, plasmaphereses, cyclofosfamide, rituximab, cyclosporine A, mofetil mycophenolate, IVIG), on October 12, 2005 (day +296), it was decided to perform a splenectomy, which had no effect. On the fourth day after the splenectomy the patient died. Histopathological examination of the spleen confirmed multifocal agglomerations of neoplastic cells (myelosis leukemica) and hemorrhagic fields.

\section{MATERIALS AND METHODS}

Whole citrated blood was used for virological investigations of HHV-5. Blood was taken at one-week intervals, starting from the second day after transplantation. Qualitative PCR for detecting HHV-5 was performed with $10 \mu$ of DNA extracted from the patient's blood using a DNA Mini Kit (Qiagen ${ }^{\circledR}$ ) according to manufacturer's instruction. Amplification was carried out in a final volume of $50 \mu \mathrm{l}$ [4]. DNA of HHV-5 strain Ad169 was used as a positive control and DNA isolated from the uninfected normal cell line HFFF-2 as a negative control.

Initially, the number of HHV-5 DNA copies in positive samples was estimated using an Eclipse ${ }^{\circledR} \mathrm{CMV}$ DNA Detection Kit (IQ Products ${ }^{\circledR}$ ), a quantitative method based on PCR/hybridization/colorimetric detection of the product, according to the manufacturer's instructions. For the confirmation of quantitative results of viremia detection, real-time PCR was used.
Detection was made in a LightCycler 2.0 instrument (Roche Diagnostics ${ }^{\circledR}$ ) using a CMV LC PCR quantitative commercial kit $\left(\right.$ Artus $\left.^{\circledR}\right)$. Fluorochrome-labeled probes, complementary to the sequence lying within the amplified PCR product, were used in this test. The range of the control DNA calibrators was between 500 and 500,000 copies $/ \mathrm{ml}$. In accordance with the manufacturer's recommendations, every sample was examined twice.

\section{RESULTS AND DISCUSSION}

Amplification of DNA isolated from blood using HHV-5-specific PCR [4] resulted in specific products detected in samples taken between days 43 and 65 after UCB transplantation (Fig. 2). The quantitative results obtained by the Eclipse ${ }^{\circledR}$ CMV Detection Kit indicated an initial increase in viremia level and its subsequent decrease, probably resulting from the introduction of antiviral therapy (Fig. 3). Similar results were recorded with the real-time PCR method, but in this case increased detection sensitivity was observed, especially in the final stage of infection, when low-copy viremia was noted (Fig. 3).

In this study we compared two methods applied for the quantitative detection of cytomegalovirus DNA: the Eclipse $^{\circledR}$ CMV DNA Detection Kit (PCR/hybridization/colorimetry) and real-time PCR using the CMV LC PCR quantitative commercial kit. The greatest difference in the results obtained with real-time PCR was at the level of $5.8 \%$, in the samples where maximum viremia was observed. In the same samples, the results of real-time PCR and the second method, based on $\mathrm{PCR} /$ hybridization/colorimetry, expressed as the number of viral DNA copies per milliliter of blood, differed by $16 \%$. It seems that both methods are comparable in terms of their sensitivity and ability to detect low-copy-number HHV-5 viremia. However, real-time PCR has one major advantage: it is much less time and lab-work consuming. With real-time PCR, sample preparation and test performance takes approximately $2.5 \mathrm{~h}$, while the time required to complete an examination using the

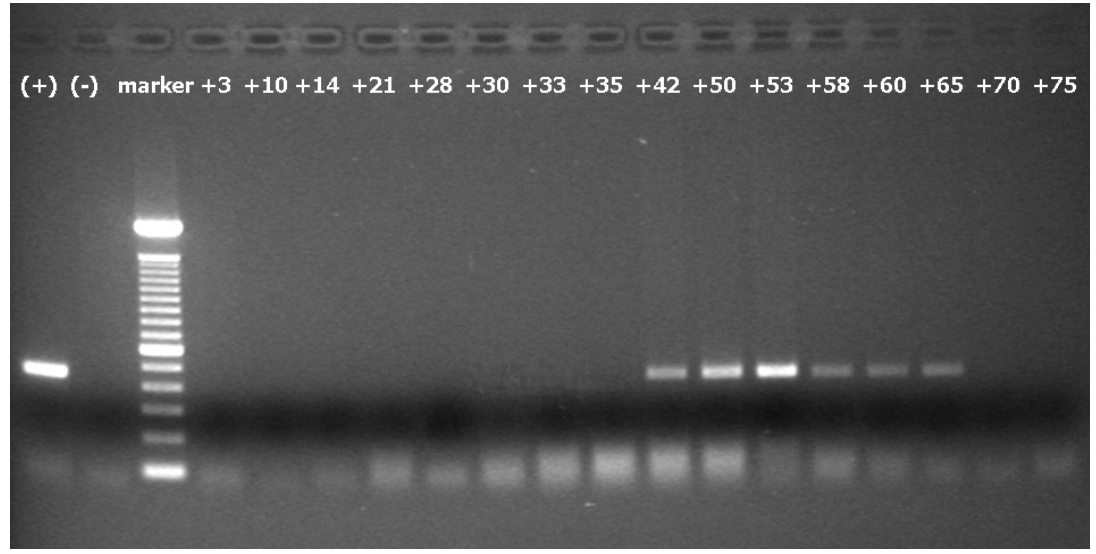

Fig. 2. PCR qualitative detection of HHV-5. Product electrophoresis was performed on $1 \%$ agarose gel stained with ethidium bromide. 


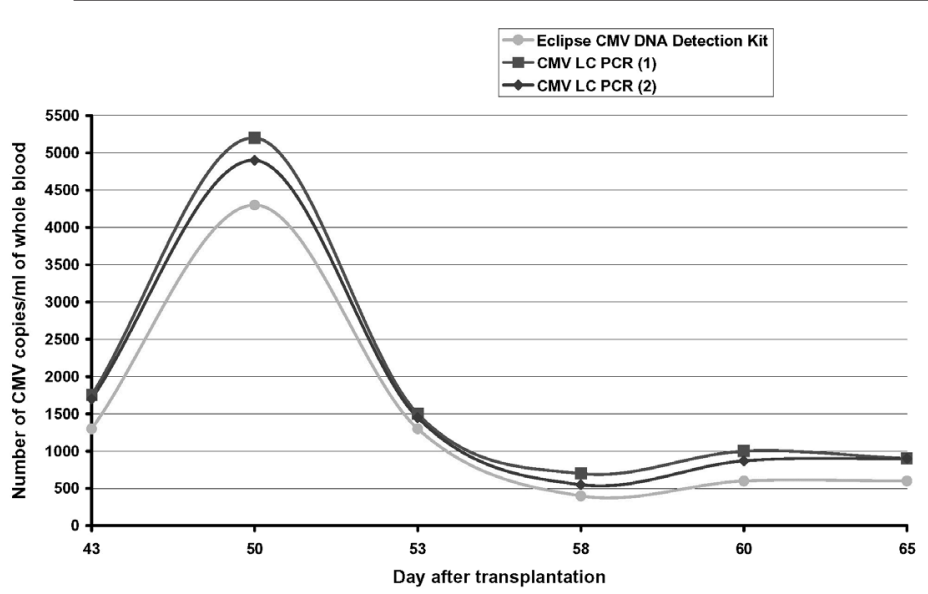

Fig. 3. Changes in HHV-5 viremia level during virus reactivation onset.

Eclipse ${ }^{\circledR}$ CMV DNA Detection Kit took two workdays. The latter method is also more sensitive to laboratory errors. The comparison of the two methods used in the present study indicates that employing real-time PCR is advisable in common post-transplantation diagnostics. Its sensitivity level guarantees detection of virus reactivation even when it is present in the blood at a low-copy level [15]. In addition, the convenience of use and the short time of test performance make this method suitable for both screening and monitoring cytomegalovirus DNA level.

Immediate detection of virus DNA in the blood allows early introduction of the proper antiviral therapy. The efficacy of hemotherapy depends considerably on the virus replication level in the blood cells [5] and usually decreases together with the time passed from the beginning of infection. Ganciclovir therapy, which is routinely used despite its myelotoxic activity, often does not give the desired outcomes because of the growing number of resistant strains of HHV-5 [11]. Still, ganciclovir remains the therapy-of-choice in the preemptive strategy. Foscarnet is considered an equivalent drug in the preemptive strategy for patients with HHV-5 reactivation after hempoietic cell transplantation. This drug elicits resistance in HHV-5 strains much more slowly and is also much less myelotoxic than ganciclovir, but because of its nephrotoxicity, foscarnet is also burdening to the patient [11]. It is thus important to reduce drug administration with decreasing number of detected viral DNA copies. One point of view is that initial therapy should be given to the patient for at least two weeks, and only after this period can one start to consider the problem of viral resistance; an earlier change of the drug is not advised [1]. On the other hand, taking into account the probability of latent virus reactivation, antiviral drug toxicity, therapy costs, and the risk of initial viral resistance, it is highly recommended to use a detection method characterized by the highest available sensitivity and specificity as well as the development of an efficient and reproducible method able to detect mutations responsible for HHV-5 resistance against the nucleoside analogues used in therapy.

\section{REFERENCES}

1. Apperley J., Carreras E. and Gluckman E. (2004): Haemopoetic stem cell transplantation. In The EBMT Handbook 2004. Forum Service Editore, Genoa, 79-90.

2. Apperley J., Carreras E. and Gluckman E. (2004): Haemopoetic stem cell transplantation. In The EBMT Handbook 2004. Forum Service Editore, Genoa, 257-268.

3. Arcese W., Rocha V., Labopin M., Sanz G., Iori A. P., de Lima M., Sirvent A., Busca A., Ionescu I., Wernet P., Gluckman E. and Eurocord-Netcord Tranplant group (2006): Unrelated cord blood transplants in adults with hematologic malignancies. Haematologica, 91, 223-230.

4. Demmler G. J., Buffone G. J., Schimbor C. M. and May R. A. (1988): Detection of cytomegalovirus in urine from newborns by using polymerase chain reaction DNA amplification. J. Infect. Dis., 158, 1177-1184.

5. Emery V. C. (2001): Investigation of CMV disease in immunocompromised patients. J. Clin. Pathol., 54, 84-88.

6. George M. J., Snydman D. R., Werner B. G., Griffith J., Falagas M. E., Dougherty N. N. and Rubin R. H. (1997): The independent role of cytomegalovirus as a risk factor for invasive fungal disease in orthotopic liver transplant recipients. Am. J. Med., 103, 106-113.

7. Gluckman E. (2005): Unrelated adult cord blood transplants for adults with acute leukemia: comparison with other stem cell sources. Biol. Blood Marrow Transplant., 11, 928 .

8. Gratwohl A., Hermans J., Goldman J. M., Arcese W., Carreras E., Devergie A., Frassoni F., Gahrton G., Kolb H.-J., Niederwieser D., Ruutu T., Vernant J. P., de Witte T. and Apperley J. (1998): Risk assessment for patients with chronic myeloid leukaemia before allogenic blood or marrow transplantation. Lancet, 352, 1087-1092.

9. Griffiths P. D., Clark D. A. and Emery V. C. (2000): Betaherpesviruses in transplant recipients. J. Antimicrob. Chemother., 45, 29-34.

10. Hamza N. S., Lisgaris M., Yadavalli G., Madeai L., Fox R., Fu P., Lazarus H. M., Koc O. N., Salata R. A. and Laughlin M. J. (2004): Kinetics of myeloid and lymphocyte recovery and infectious complications after unrelated umbilical cord blood versus HLA-matched unrelated donor allogenic transplantation in adults. Br. J. Haematol., 124, 488-498.

11. Reusser P., Einsele H., Lee J., Volin L., Rovira M., Engelhard D., Finke J., Cordonnier C., Link H. and Ljungman P. (2002): Randomized multicenter trial of foscarnet versus ganciclovir for preemptive therapy of cytomegalovirus infection after allogenic stem cell transplantation. Blood, 99, 1159-1164.

12. Roizman B. (1992): The family Herpesviridae: an update. Arch. Virol., 123, 425-449.

13. Sanz G. F. (2005): Unrelated donor umbilical cord blood transplantation in adults with hematologic malignancies. Pathol. Biol., 53, 165-166.

14. Sanz G. F., Moscardo F. and Jimenez C. (2004): Unrelated-donor cord blood transplantation in patients with chronic myeloid leukemia. Biol. Blood Marrow Transplant., 10, 734.

15. Schaade L., Kockelkorn P., Ritter K. and Kleines M. (2000): Detection of cytomegalovirus DNA in human spec- 
imens by LightCycler PCR. J. Clin. Microbiol., 38, 4006-4009.

16. Torok-Storb B., Boeckh M., Hoy C., Leisenring W., Myerson D. and Gooley T. (1997): Association of specific cytomegalovirus genotypes with death from myelosuppression after marrow transplantation. Blood, 90, 2097-2102.
17. Tse W. and Laughlin M. J. (2005): Umbilical cord blood transplantation: a new alternative option. Hematology Am. Soc. Hematol. Educ. Program, 377-383.

18. Wagner J. E. and Barker J. (2004): Umbilical cord blood transplantation: novel approaches toward improving engraftment. Biol. Blood Marrow Transplant., 10, 733. 
